Article

\title{
Supervision after Certification: An Evolutionary Game Analysis for Chinese Environmental Labeled Enterprises
}

\author{
Jie Jin ${ }^{1,2,3}$, Jun Zhuang ${ }^{3, *(1)}$ and Qiuhong Zhao ${ }^{1,4}$ \\ 1 School of Economics and Management, Beihang University, Beijing 100191, China; jjin8@buffalo.edu (J.J.); \\ qhzhao@buaa.edu.cn (Q.Z.) \\ 2 Beijing Key Laboratory of Emergency Support Simulation Technologies for City Operations, \\ Beijing 100091, China \\ 3 Department of Industrial and System Engineering, University at Buffalo, Buffalo, NY 14260, USA \\ 4 Beijing International Science and Technology Cooperation Base for City Safety Operation and Emergency \\ Support, Beijing 100091, China \\ * Correspondence: jzhuang@buffalo.edu
}

Received: 5 March 2018; Accepted: 5 May 2018; Published: 9 May 2018

check for updates

\begin{abstract}
An eco-labeling scheme is a method of environmental performance certification that is beneficial for reducing negative environmental impacts and promoting green consumption. Many types of research studies have shown its effectiveness. However, to the best of our knowledge, fewer studies have considered how to supervise and regulate the enterprises after getting certificated. An enterprise may have obtained certification that its product meets the corresponding environmental standards, but without effective supervisions and regulations, it may not continue to implement the standards after being certified. Such behaviors are not only unfavorable to environmental protection, they also harm the eco-labeling scheme. With the consideration that different eco-labeling schemes and standards would result in different interaction relationships among stakeholders, we focus on Chinese Environmental Labeling (CEL), which is a government-sponsored scheme. By utilizing the approach of evolutionary game theory, we built a model including the government agency and enterprise and their strategic interactions. Numerical analyses are applied to verify the modeling analyses and demonstrate the influences of game parameters. Our results indicate that supervisions from the government side are necessary in order for the enterprises to implement the standards, but high supervision costs and low efficiency are the main factors that prevent the government agency from getting more involved. Reducing the executing costs of the enterprises would prompt them to participate more. Additionally, if the government agencies and customers could have a bigger, more positive influence on the enterprises, then the enterprises would likely choose to implement the standards. Our results provide references for the better development of an eco-labeling scheme as well as government environmental policy-making.
\end{abstract}

Keywords: eco-labeling; system dynamics; evolutionary game theory; environmental regulation

\section{Introduction}

Eco-labeling schemes are always launched by governments and other organizations to differentiate between enterprises that apply green processes and those that do not. Nowadays, with the public becoming more concerned about the influences of their daily activities on the environment, eco-labeling has become an effective tool for individual customers verifying the environmental friendliness claimed by enterprises [1,2]. 
More eco-friendly consumption patterns could be promoted through eco-labeling. Consumers are informed about the environmental effects of the products, and are encouraged to reduce the environmental damages by changing their purchasing choices [3]. In addition, products with eco-labels are required to implement higher standards in general. Therefore, eco-labeled products tend to have a higher quality compared with parallel products, which is an important factor motivating customers to pay a premium. This situation is particularly obvious in the food and textile industries $[4,5]$.

To cater to customer demand and improve product competitiveness, more and more producers choose to join eco-labeling schemes and invest in more sustainable practices. However, on the other hand, we should notice that the deficiencies regarding supervision and an imperfect regulation system have also created opportunities for the misuse of the eco-label in the market [6-8], which have damaged the credibility of eco-labeling schemes to a large extent $[2,9,10]$. For instance, over half of final United States (US) consumers have expressed a level of distrust about a product's green degree as conveyed by its eco-label [11]. Similarly, consumers also doubt the credibility of eco-labels in some developing countries, such as China and Malaysia [2,8].

From a theoretical viewpoint, the misuse of eco-label is greenwashing, which is a long-term research question, and a prevalent problem worldwide. However, as far as we know, most of the corresponding research studies in this field focus on issues such as fake or over-advertising problems [12-15], the influences of multiple certification systems and diverse standards [16-19], and supervision costs [20-22]. Few studies have considered how to regulate and supervise the eco-labeled enterprises after certification. An enterprise may have been granted that its product meets the environmental standards, but it may not follow the environmental standards after getting certified.

This pervasive problem does not only exist in developing countries, it is also reported frequently in developed countries $[2,8,21]$. It is clear that this kind of behavior is harmful to both the environment and eco-labeling schemes $[13,23]$. Not only would customer confidence in the eco-label decrease with the dishonest behaviors of involved enterprises, but incentives for other prospective enterprises to participate would also go down due to the less valuable scheme. From this point of view, measures should be adopted by governments to deal with it.

However, more supervision from the government side alone would be insufficient. For the complexity and dynamics of production, it is hard for the government to implement effective supervision [3,24]. Fundamentally speaking, conflicting interests among stakeholders are the primary cause for this unfavorable situation $[9,18]$. From the perspective of policymakers, they hope for more green actions from enterprises. However, without considering spontaneous social responsibility, which is extremely scarce among enterprises $[25,26]$, there is little incentive for an enterprise to take costly environmental measures on its own. To eliminate the double marginalization effects between policymakers and enterprises, the strategic interactions between them should be analyzed. Motivated by this, we built a game model to reflect their interaction relationships, and study how to coordinate their behaviors.

Game theory has frequently been employed to study the strategic interactions among stakeholders in similar areas. However, in most studies, there is an important hypothesis on the players: they are considered intelligent and rational, which is inconsistent with the actual situation. On the other hand, the dynamic process of the game is often neglected. In fact, eco-labeled enterprises and policymakers are bounded by rationality and change their strategies dynamically by observing and comparing payoffs with others.

To overcome the disadvantages as mentioned earlier of traditional game theory, evolutionary game theory (EGT) was developed. Inspired by the biological evolutionary process, EGT combines game theory with dynamic evolution process analysis, and focuses more on the dynamics of strategy change as influenced by the strategy frequency in the population $[27,28]$. Replicator dynamics are used to represent the learning and evolution mechanism of individuals in the process [29]. Using the replicator equation, EGT can guarantee that the players are using the evolutionarily stable strategy in 
the equilibrium point [30]. Given this, the evolutionary game model is utilized in this paper to reflect the bounded rationality of players and their dynamic process of strategy choosing.

In addition, we should notice that the existing eco-labeling schemes in different countries are very different, and different certification systems and standards would result in different interaction relationships among stakeholders $[3,8,17,31,32]$. Regarding this point, we focus on Chinese Environmental Labeling (CEL) which is an eco-labeling scheme sponsored by the Chinese government. It is also one of the most influential and authoritative eco-labeling schemes in China. Based on the modeling analyses, some policy suggestions are proposed, which would benefit a better development of eco-labeling scheme as well as government environmental policy-making.

Although our research is mainly motivated by the issues that exist in China, the analyses and proposed policy suggestions are also suitable for many countries, especially some large developing countries. A series of government-sponsored eco-labeling schemes have been established in these countries recently, and similar problems have also been encountered by their governments $[8,33,34]$.

The remainder of this paper is organized as follows: Section 2 presents a brief presentation of the CEL scheme. Section 3 introduces its notions, assumptions, and parameters. Section 4 provides the mathematical model and corresponding analyses of the studied problems. In Section 5, a numerical analysis is conducted to supplement the analyses in Section 4 and demonstrate the influences of the game's parameters. Section 6 summarizes the paper and proposes several policy suggestions, and Appendixs A-C provide the proofs to the propositions.

\section{A Description to CEL}

The Chinese Environmental Labeling (CEL) scheme was launched by the Ministry of Environmental Protection of the People's Republic of China (MEP) in 1993. As shown in Figure 1, the label consists of the sun, a green hill, and water in the center encircled by 10 rings, which represent the public. The moral of the label is that we should act together to protect our planet.

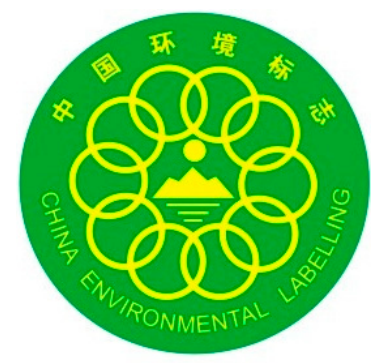

Figure 1. The logo of the Chinese Environmental Labeling (CEL) scheme.

At present, about 4000 enterprises and 200,000 products have been verified. From August 2001, CEL started to follow the regulations of ISO 14024. Compared with other eco-labeling schemes in China, CEL requires that labeled products are not only qualified but also have fewer environmental impacts than parallel products. It is a full life-cycle activity from product design, production, packaging, and transportation to consumption and recirculation [35]. Remarkable results have been acquired in the printing and ceramic industries. The development process of CEL is presented in Figure 2.

The general certification process of CEL is: a prospective enterprise submits a request as well as the required corresponding testimonial materials to the China Environmental United Certification Center (CEC). If qualified, the enterprise needs to pay the certification fees and sign a contract with the CEC. Then, a check panel would be sent by the CEC to the enterprise's actual production field. The panel conducts on-site investigations to the enterprise, and sends selected samples to a CEC-affiliated testing organization for further testing. Based on the materials submitted by the enterprise, results of the field investigation and sample test results from the testing organization, the check panel makes a report and 
submits it to the technical committee of the CEC. The technical committee summarizes the results of the investigation and decides.

If approved, the enterprise would be authorized to use CEL for three years. The enterprise can print the label on the packaging of its products. At the same time, labeled products have priority for government procurement (in 2006, the Ministry of Finance of the People' s Republic of China (MOF) issued rules requiring government agencies to give priority to CEL products). In general, the CEC would inspect the enterprise annually, and the local administrations for industry and commerce (AIC) also have supervision duties. The supervision results of the AIC would be reported to the CEC. If an enterprise were found to not implement the standards, the CEC would issue fines to it. After three years, the enterprise needs to resubmit materials and accepts recertification. The specific processes are presented in Figure 3.

From Figure 3, we can see that the certification and supervision process design of CEL seems to be rigorous. However, given that the CEC and AIC need to supervise thousands of scattered enterprises and hundreds of thousands of different products, workforce and material resources are limited for it to implement effective supervisions. Regarding this, the motivations for authorized enterprises to implement standards continuously should be analyzed, and the strategic interactions between the enterprises and government agencies should be coordinated, so that a more efficient supervision system could be formulated by the government.

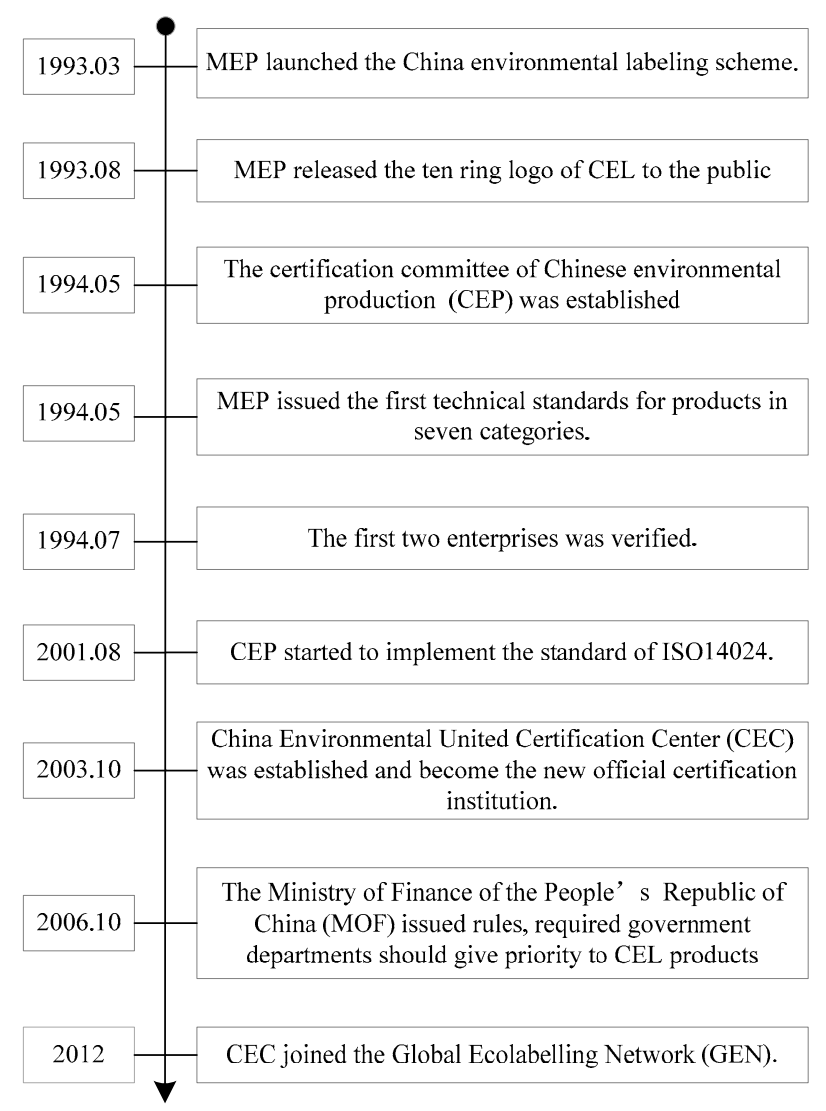

Figure 2. Development process of the CEL. MEP: Ministry of Environmental Protection of the People's Republic of China. 


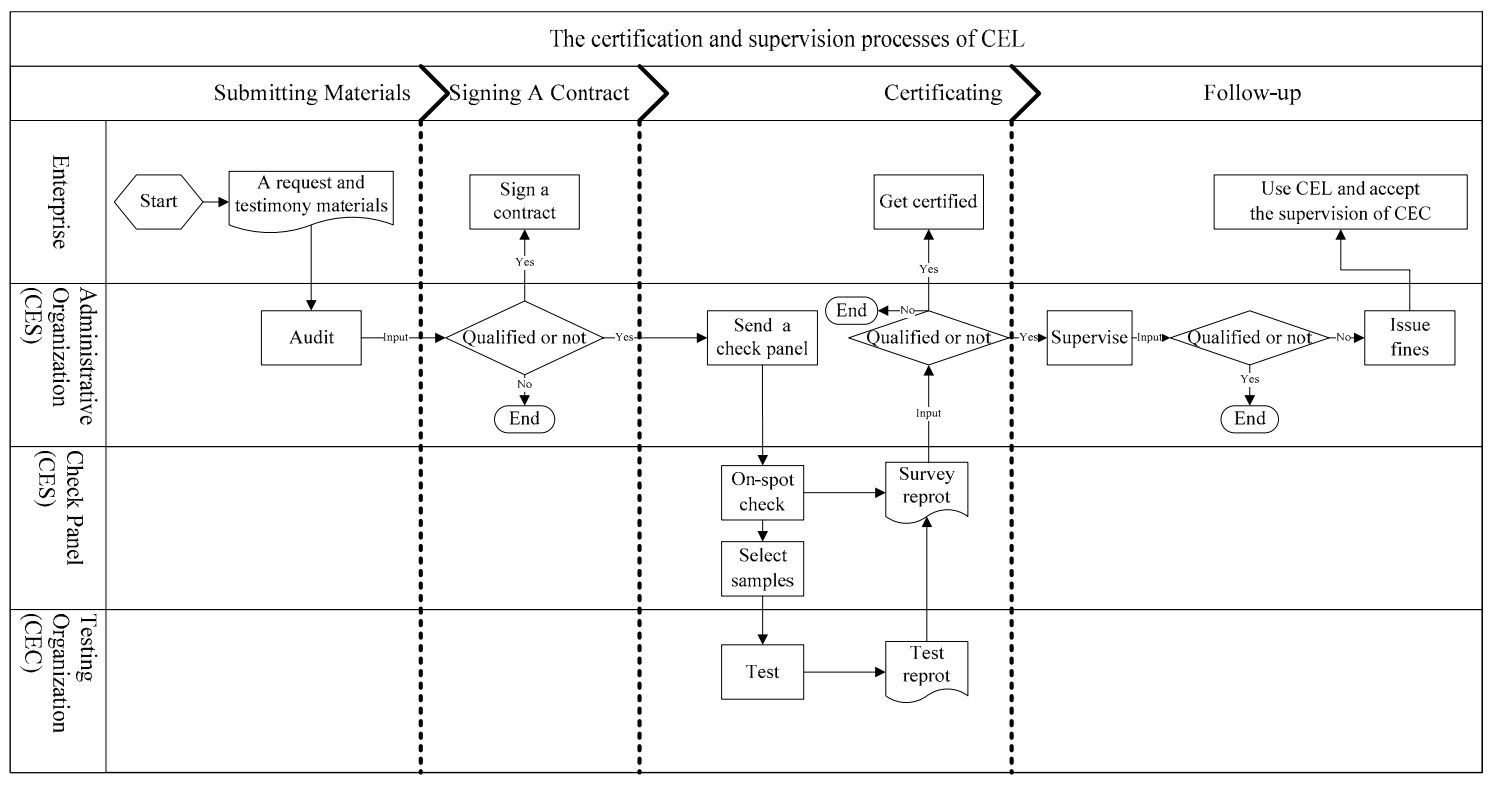

Figure 3. The certification and supervision processes of CEL.

\section{Notions, Assumptions, and Parameters}

Regarding the contents of Section 2, the stylized modeling scenario in this paper is: after the certification process, the enterprises are authorized to use the CEL. Government agencies such as the CEC and the AIC act as supervisors. We consider an evolutionary game model including the government agencies and enterprises. Based on the theory of the evolutionary game, government agencies and enterprises are treated as separate players. They choose their strategies simultaneously, and neither of them can observe the other player's choice when they make their decision. Their strategic interactions can be viewed as an asymmetric repeated game.

The pure strategy set of the government agency consists of two alternative strategies: supervise $\left(A_{1}\right)$ and do not supervise $\left(A_{2}\right)$. The government agency adopts strategy $A_{1}$ with the probability of $x(0 \leq x \leq 1)$, and the opposite strategy with $1-x$. Similarly, the pure strategy set of the enterprise also consists of two alternative strategies: implement $\left(B_{1}\right)$ and do not implement $\left(B_{2}\right)$. The probability of the enterprise choosing the strategy $B_{1}$ is $y(0 \leq \mathrm{y} \leq 1)$, and the probability of non-implementation is $1-y$.

The government agency sets a series of standards for the enterprise, and supervises its implementation. The environmental benefits that the government department could obtain from the cleaner production of the enterprise are defined as $W$. The more actions that the government agency takes, the more trusts from the public would develop towards the CEL scheme, and more prospective enterprises would be willing to join the scheme. We use $L_{1}$ to denote the benefits that the government agency could obtain from the public side if it chose strategy $A_{1}$.

The supervision costs of the government agency are defined as $C_{1}$. If the enterprise chose not to implement the standards, the probability of its behaviors being detected by the government agency was $q\left(C_{1}\right) . q$ is monotonically increasing with $C_{1}$. If the government department found out that the authorized enterprise did not implement the standards, the government department would issue fines $(F)$ to it.

Based on some popular understandings, the following assumptions are proposed.

Assumption 1. $q\left(C_{1}\right)$ is a continuous function and $q\left(C_{1}=0\right)=0$. We assume that $\frac{\partial q\left(C_{1}\right)}{\partial C_{1}}>0$ and $\frac{\partial^{2} q\left(C_{1}\right)}{\partial C_{1}{ }^{2}}<0$, which means that the detection probability increases with the supervision costs of the government agency. 
The sketch diagram of $q\left(C_{1}\right)$ is depicted as Figure 4 . To facilitate the analysis, we assume that $q\left(C_{1}\right)=1-e^{-C_{1} / R}$ and $R$ is a constant that reflects the supervision effectiveness of the government agency [36].

For the enterprises, there is a basic hypothesis:

Assumption 2. Enterprises' production has a negative impact on the state of the environment, and a cleaner production is more expensive than the normal production [37]. It means that a higher cost $\left(C_{2}\right)$ is needed for implementing the standards strictly.

The benefits from the customer side for the enterprise choosing to participate in the eco-labeling scheme are denoted as $P_{1}$, which comes from the premium for labeled products and the environmental considerations of consumers [38]. As mentioned in Section 2, CEL-labeled products have the priority for government procurement; so, we use $P_{2}$ to denote the benefits from the government side. The enterprise could always obtain the benefits of $P_{1}$ and $P_{2}$ unless it did not implement the standards, and its behavior was detected by the government agency.

As depicted in Table 1, the decision variables and parameters are explained as follows.

Table 1. Definitions of the notations used in the paper.

\begin{tabular}{ll}
\hline For Government Agency \\
\hline$x$ & Decision variable, the probability of choosing strategy $A_{1}$ \\
$W$ & Environmental benefits from the cleaner production \\
$L_{1}$ & Benefits from the public side for choosing strategy $A_{1}$ \\
$F$ & Fines for the non-execution act \\
$C_{1}$ & Implementation costs for supervision \\
\hline For Enterprise & \\
\hline$y$ & Decision variable, the probability of choosing strategy $B_{1}$ \\
$P_{1}$ & Benefits from the customer side due to participating in the scheme \\
$P_{2}$ & Benefits from the government side due to participating in the scheme \\
$C_{2}$ & Implementation costs for cleaner production \\
$q$ & The probability that the non-execution act was discovered \\
\hline Others & \\
\hline$R$ & A constant that reflected the supervision effectiveness of the government agency \\
\hline
\end{tabular}

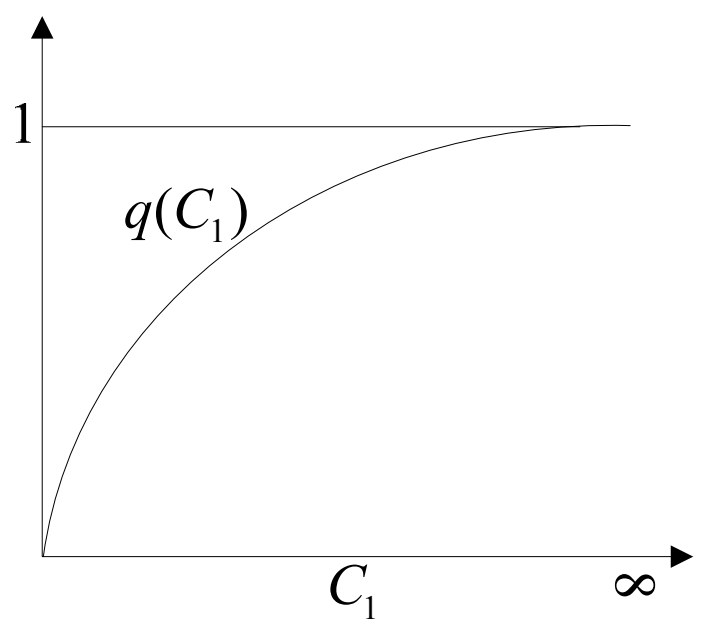

Figure 4. The sketch diagram of $q\left(C_{1}\right)$. 


\section{Game Model}

\subsection{The Model}

Regarding the content in Section 3, the payoffs of the government agency and the enterprise are presented in Table 2. As depicted in Table 2, in the scenario of $\left(A_{1}, B_{2}\right)$, the government agency chooses to implement supervision, and the enterprise chooses not to implement the standards. For the government agency, it costs $C_{1}$ to implement supervision and gains $L_{1}$ from the public side. If the enterprise was found to have not implemented the standards (the probability of its non-execution act discovered by the government agency was $q$ ), the government agency would impose a fine $(F)$ to the enterprise and order it to make corrections. If the government agency could not find the non-execution acts of the enterprise, it could not obtain the environmental benefits. In this scenario, the expected payoffs of the government agency are $-C_{1}+q(F+W)+L_{1}$.

Table 2. Payoff matrix.

\begin{tabular}{ccc}
\hline \multirow{2}{*}{ Government Agency } & \multicolumn{2}{c}{ Enterprise } \\
\cline { 2 - 3 } & $\boldsymbol{B}_{\mathbf{1}}$ & $\boldsymbol{B}_{\mathbf{2}}$ \\
\hline$A_{1}$ & $\left(-C_{1}+L_{1}+W,-C_{2}+P_{1}+P_{2}\right)$ & $\left(-C_{1}+q(F+W)+L_{1},-q F+(1-q)\left(P_{1}+P_{2}\right)\right)$ \\
$A_{2}$ & $\left(W,-C_{2}+P_{1}+P_{2}\right)$ & $\left(0, P_{1}+P_{2}\right)$ \\
\hline
\end{tabular}

To the enterprise, if its non-execution acts were discovered, it would be fined $F$. Whereas if not, the enterprise could still gain benefits from the customer and government sides. In this scenario, the expected payoffs are $-q F+(1-q)\left(P_{1}+P_{2}\right)$. The other formulas in Table 2 are derived in a similar way, and are thus skipped here.

In terms of Table 2 , the fitness of the government agency choosing strategy $A_{1}$ and $A_{2}$ are:

$$
\begin{gathered}
U_{A 1}=y\left(-C_{1}+W+L_{1}\right)+(1-y)\left[-C_{1}+q(F+W)+L_{1}\right] \\
U_{A 2}=y W
\end{gathered}
$$

We use $U_{A 1}$ to represent the fitness of the government agency choosing the strategy $A_{1}$, and $U_{A 2}$ represents the fitness of choosing $A_{2}$. Thus, the average fitness of the government agency can be obtained as follows:

$$
U_{A}=x U_{A 1}+(1-x) U_{A 2}
$$

Similarly, the fitness of the enterprise choosing the strategies $B_{1}$ and $B_{2}$ are:

$$
\begin{gathered}
U_{B 1}=x\left(-C_{2}+P_{1}+P_{2}\right)+(1-x)\left(-C_{2}+P_{1}+P_{2}\right) \\
U_{B 2}=x\left[-q F+(1-q)\left(P_{1}+P_{2}\right)\right]+(1-x)\left(P_{1}+P_{2}\right)
\end{gathered}
$$

$U_{B 1}$ represents the fitness of the enterprise choosing the strategy $B_{1}$, and $U_{B 2}$ represents the fitness of choosing $B_{2}$. Thus, the average fitness of the enterprise can be obtained as follows:

$$
U_{B}=y U_{B 1}+(1-y) U_{B 2}
$$

In a replicator dynamic system, the growth rate of a strategy chosen by a player would be equal to its fitness, less the average fitness among each player [39]. For the government agency, the change rate of $x$ is $f_{A}=\frac{d x}{d t}=x\left(U_{A 1}-U_{A}\right)$. Substituting Equations (1) and (3) into it, and adding some elementary algebra results in:

$$
f_{A}=x(1-x)\left[-C_{1}+L_{1}+(1-y) q(F+W)\right]
$$


Similarly, we can obtain:

$$
f_{B}=y(1-y)\left[q x\left(F+P_{1}+P_{2}\right)+C\right]
$$

Equations (7) and (8) form the continuous frequency dynamic system of this evolutionary game. When $f_{A}=0$ and $f_{B}=0$, it means that the speed of strategy adjustment is equal to zero, and the system reaches a relatively stable equilibrium state. As presented in Formula (9), the dynamic equation set can be obtained as follows:

$$
\left\{\begin{array}{l}
\frac{d x}{d t}=x(1-x)\left[-C_{1}+L_{1}+(1-y) q(F+W)\right]=0 \\
\frac{d y}{d t}=y(1-y)\left[q x\left(F+P_{1}+P_{2}\right)+C=0\right.
\end{array}\right.
$$

By solving Equation (9), five local equilibrium points (LEP) from the system are obtained: $A(0,0)$, $\mathrm{B}(0,1), \mathrm{C}(1,0), \mathrm{D}(1,1), \mathrm{E}\left(x^{*}, y^{*}\right)$. Among them:

$$
\left\{\begin{array}{l}
x^{*}=\frac{C_{2}}{q\left(F+P_{1}+P_{2}\right)} \\
y^{*}=\frac{q\left[F+(1-\alpha) W+L_{2}\right]-C_{1}+L_{1}}{q(F+W)}
\end{array}\right.
$$

The Jacobian matrix $(J)$ of the game is presented by Formula (11):

$$
J=\left\{\begin{array}{ll}
\frac{\partial f_{A}}{\partial x} & \frac{\partial f_{A}}{\partial y} \\
\frac{\partial f_{B}}{\partial x} & \frac{\partial f_{B}}{\partial y}
\end{array}\right\}
$$

Thereinto:

$$
\begin{gathered}
\frac{\partial f_{A}}{\partial x}=(1-2 x)\left(-C_{1}+L_{1}+(1-y) q(F+W)\right) \\
\frac{\partial f_{A}}{\partial y}=-q x(1-x)(F+W) \\
\frac{\partial f_{B}}{\partial x}=y(1-y) q\left(F+P_{1}+P_{2}\right) \\
\frac{\partial f_{B}}{\partial y}=(1-2 y)\left(x q\left(F+P_{1}+P_{2}\right)-C_{2}\right)
\end{gathered}
$$

According to Friedman [29], A, B, C, and D are local pure strategy equilibrium points, E is a mixed local strategy equilibrium point, and the stability of them can be obtained by analyzing the Jacobian matrix's determinant $(\operatorname{det} J)$ and trace of the game $(\operatorname{tr} J)$. The specific values of $\operatorname{det} J$ and $\operatorname{tr} J$ of $J$ in the above five points are presented in Appendix A.

For a certain point, if $\operatorname{det} J>0$ and $\operatorname{tr} J<0$, this point satisfies the ESS (evolutionary stable state) condition, and it has the asymptotic stability. Thus, the corresponding strategy combination is a stable equilibrium solution. If $\operatorname{det} J \geq 0$ and $\operatorname{tr} J>0$, this point is unstable. If $\operatorname{det} J>0$ and $\operatorname{tr} J=0$, this point is neutral. If $\operatorname{det} J<0$, this point is a saddle point [40,41]. In terms of Table A1 in Appendix A, the proposition below can be derived.

Proposition 1. The strategy combination $\left(A_{2}, B_{1}\right)$ would not be a stable equilibrium solution.

Remark 1. The proof to Proposition 1 is presented in Appendix B. Without the influences from the government and public side, a for-profit enterprise would not implement the environmental standards spontaneously. Supervisions from the government agencies are necessary to keep the CEL scheme working smoothly.

In this section, we obtain the fitness functions to specify the strategic interactions between the government agencies and enterprise. As shown in Table A1, whether a certain point is a stable point, 
a neutral point, or a saddle point is determined by the size of the relationships among the parameters. In the next section, we study the possible scenarios one by one, analyze the conditions for the different equilibrium states, and explain their corresponding practical significance.

\subsection{Model Analysis}

In terms of the contents in Section 3 and Table A1, there would be altogether six possible scenarios in this game, according to the size relationships between the costs and benefits of the players.

\subsubsection{Scenario I}

When $L_{1}>C_{1}$ and $q\left(F+P_{1}+P_{2}\right)>C_{2}$, the state of five local equilibrium points can be shown in Table 3.

Table 3. State analysis of local equilibrium points (LEP). ESS: evolutionary stable state.

\begin{tabular}{cccc}
\hline LEP & $\operatorname{det} J$ & trJ & State \\
\hline $\mathrm{A}(0,0)$ & - & uncertain & saddle \\
$\mathrm{B}(0,1)$ & + & + & unstable \\
$\mathrm{C}(1,0)$ & - & uncertain & saddle \\
$\mathrm{D}(1,1)$ & + & - & ESS \\
$\mathrm{E}\left(x^{*}, y^{*}\right)$ & + & 0 & neutral \\
\hline
\end{tabular}

As depicted in Table A1, for A $(0,0)$, $\operatorname{det} J=\left[-C_{1}+L_{1}+q(F+W)\right]\left(-C_{2}\right)$, and $\operatorname{tr} J=-C_{1}+L_{1}+q(F+W)-C_{2}$. When $L_{1}>C_{1}$ and $q\left(F+P_{1}+P_{2}\right)>C_{2}$, this results in $-C_{1}+L_{1}+q(F+W)>0 \Rightarrow \operatorname{det} J<0$. In this case, $A(0,0)$ is a saddle point. Other formulas in Table 3 are derived in a similar way and skipped here.

Proposition 2. Under the condition that $L_{1}>C_{1}$ and $q\left(F+P_{1}+P_{2}\right)>C_{2}, D(1,1)$ is the ESS point.

Remark 2. In this scenario, the government agency chooses to supervise, and the enterprise chooses to implement the standards. From an overview viewpoint, parameters $q, F, W$, and $L_{1}$ can be viewed as the "positive factors" for the government agency choosing a strategy $A_{1}$, and $C_{1}$ can be viewed as the "negative factor". Similarly, to the enterprise, $q, F, P_{1}$, and $P_{2}$ can be viewed as the "positive factors" for the enterprise choosing strategy $B_{1}$, and $C_{2}$ can be viewed as the "negative factor". Under the condition that $L_{1}>C_{1}$ and $q\left(F+P_{1}+P_{2}\right)>C_{2}$, both the government agency and enterprise have motivations to fulfill their duty.

According to the equilibrium state analysis in Table 3, the evolution paths of $\mathrm{A} \sim \mathrm{E}$ in scenario 1 can be depicted by panel (a) in Figure 5. In phase portrait I, we can see that with a neutral point $\mathrm{E}$ $\left(x^{*}, y^{*}\right)$ in the center, the point $\mathrm{B}(0,1)$ acts as the "source", and point $\mathrm{D}(1,1)$ acts as the "sink". A $(0,0)$ and $C(1,0)$ are two saddle points; they have the stability in one direction.

\subsubsection{Scenario II}

When $L_{1}>C_{1}$ and $q\left(F+P_{1}+P_{2}\right)<C_{2}$, the state of five local equilibrium points can be shown in Table 4.

Table 4. State analysis of LEP.

\begin{tabular}{cccc}
\hline LEP & det $J$ & trJ & State \\
\hline $\mathrm{A}(0,0)$ & - & uncertain & saddle \\
$\mathrm{B}(0,1)$ & + & + & unstable \\
$\mathrm{C}(1,0)$ & + & - & ESS \\
$\mathrm{D}(1,1)$ & - & uncertain & saddle \\
$\mathrm{E}\left(x^{*}, y^{*}\right)$ & + & 0 & neutral \\
\hline
\end{tabular}


Proposition 3. Under the condition that $L_{1}>C_{1}$ and $q\left(F+P_{1}+P_{2}\right)<C_{2}, C(1,0)$ is the ESS point.

Remark 3. In this scenario, the enterprise has fewer motivations to implement the standards, and efforts from the government agency would have no impact. The enterprise would choose not to implement the standards, although the government agency chooses to supervise. This scenario is unfavorable for the government agency. As depicted in panel (b) of Figure 5, the phase portrait is symmetric with a neutral point $E\left(x^{*}, y^{*}\right)$ at the center, a "source" at $B(0,1)$, and a "sink" at $C(1,0) . A(0,0)$ and $D(1,1)$ are two saddle points.

\subsubsection{Scenario III}

When $0<L_{1}<C_{1}-q(F+W)$ and $q\left(F+P_{1}+P_{2}\right)>C_{2}$, the state of five local equilibrium points can be shown in Table 5 .

Table 5. State analysis of LEP.

\begin{tabular}{cccc}
\hline LEP & $\operatorname{det} J$ & $\operatorname{tr} J$ & State \\
\hline $\mathrm{A}(0,0)$ & + & - & ESS \\
$\mathrm{B}(0,1)$ & - & uncertain & saddle \\
$\mathrm{C}(1,0)$ & + & + & unstable \\
$\mathrm{D}(1,1)$ & - & uncertain & saddle \\
$\mathrm{E}\left(x^{*}, y^{*}\right)$ & + & 0 & neutral \\
\hline
\end{tabular}

Proposition 4. Under the condition that $0<L_{1}<C_{1}-q(F+W)$ and $q\left(F+P_{1}+P_{2}\right)>C_{2}, A(0,0)$ is the ESS point.

Remark 4. In this scenario, the government agency tends to choose not to supervise due to high supervision costs. Without the supervisions from the government side, the enterprise would not implement the standards. As depicted in panel (c) of Figure 5 , with a neutral point $E\left(x^{*}, y^{*}\right)$ in the center, the point $C(1,0)$ acts as the "source" and point $A(0,0)$ acts as the "sink". $B(0,1)$ and $D(1,1)$ are two saddle points.

\subsubsection{Scenario IV}

When $0<L_{1}<C_{1}-q(F+W)$ and $q\left(F+P_{1}+P_{2}\right)<C_{2}$, the state of five local equilibrium points can be shown in Table 6 .

Table 6. State analysis of LEP.

\begin{tabular}{cccc}
\hline LEP & $\operatorname{det} J$ & trJ & State \\
\hline $\mathrm{A}(0,0)$ & + & - & ESS \\
$\mathrm{B}(0,1)$ & - & uncertain & saddle \\
$\mathrm{C}(1,0)$ & - & uncertain & saddle \\
$\mathrm{D}(1,1)$ & + & + & unstable \\
$\mathrm{E}\left(x^{*}, y^{*}\right)$ & + & 0 & neutral \\
\hline
\end{tabular}

Proposition 5. Under the condition that $0<L_{1}<C_{1}-q(F+W)$ and $q\left(F+P_{1}+P_{2}\right)<C_{2}, A(0,0)$ is the ESS point.

Remark 5. In this scenario, neither the government agency nor the enterprise has motivation to fulfill their duty. The CEL scheme loses the force of constraint to both participants. As depict in panel (d) in Figure 5, the phase portrait is symmetric with a neutral point $E\left(x^{*}, y^{*}\right)$ at the center, a "source" at $D(1,1)$, and a "sink" at $A(0,0) . B(0,1)$ and $C(1,0)$ are two saddle points. 


\subsubsection{Scenario V}

When $C_{1}-q(F+W)<L_{1}<C_{1}$ and $q\left(F+P_{1}+P_{2}\right)>C_{2}$, the state of five local equilibrium points can be shown in Table 7.

Table 7. State analysis of LEP.

\begin{tabular}{cccc}
\hline LEP & det $J$ & trJ & State \\
\hline $\mathrm{A}(0,0)$ & - & uncertain & saddle \\
$\mathrm{B}(0,1)$ & - & uncertain & saddle \\
$\mathrm{C}(1,0)$ & - & uncertain & saddle \\
$\mathrm{D}(1,1)$ & - & uncertain & saddle \\
$\mathrm{E}\left(x^{*}, y^{*}\right)$ & + & 0 & neutral \\
\hline
\end{tabular}

Proposition 6. Under the condition that $C_{1}-q(F+W)<L_{1}<C_{1}$ and $q\left(F+P_{1}+P_{2}\right)>C_{2}$, there is no ESS point in the game.

Remark 6. As depicted in panel (e) in Figure 5, E ( $\left.x^{*}, y^{*}\right)$ locates in the center, and the other points in four corners are on periodic trajectories circling counterclockwise. Under Malthusian dynamics, there is no ESS solution for this game.

\subsubsection{Scenario VI}

When $C_{1}-q(F+W)<L_{1}<C_{1}$ and $q\left(F+P_{1}+P_{2}\right)<C_{2}$, the state of five local equilibrium points can be shown in Table 8.

Table 8. State analysis of LEP.

\begin{tabular}{cccc}
\hline LEP & $\operatorname{det} \boldsymbol{J}$ & trJ & State \\
\hline $\mathrm{A}(0,0)$ & - & uncertain & saddle \\
$\mathrm{B}(0,1)$ & - & uncertain & saddle \\
$\mathrm{C}(1,0)$ & + & - & ESS \\
$\mathrm{D}(1,1)$ & + & + & unstable \\
$\mathrm{E}\left(x^{*}, y^{*}\right)$ & + & 0 & neutral \\
\hline
\end{tabular}

Proposition 7. Under the condition that $C_{1}-q(F+W)<L_{1}<C_{1}$ and $q\left(F+P_{1}+P_{2}\right)<C_{2}, C(1,0)$ is the ESS point.

Remark 7. Similar to Scenario II, in this scenario, the enterprise would not implement the standards spontaneously, and efforts from the government agency would have no impact. As depicted in panel (f) in Figure 5, with a neutral point $E\left(x^{*}, y^{*}\right)$ in the center, the point $D(1,1)$ acts as the "source", and point $C(1,0)$ acts as the "sink". $A(0,0)$ and $B(0,1)$ are two saddle points.

When $L_{1}=C_{1}, L_{1}=C_{1}-q(F+W)$ or $q\left(F+P_{1}+P_{2}\right)=C_{2}$, the state of five local equilibrium points can be shown in Tables A2-A10 in Appendix C. Given the limited space available and without affecting the conclusion, we would not analyze them one by one. In this section, we analyze all of the possible scenarios by dividing parameters into "negative" and "positive" influence factors. In the next section, firstly, we would employ a numerical analysis in order to verify the analyses in this section. In addition, a series of numerical analysis would also be conducted to show the influence of single game parameters. 


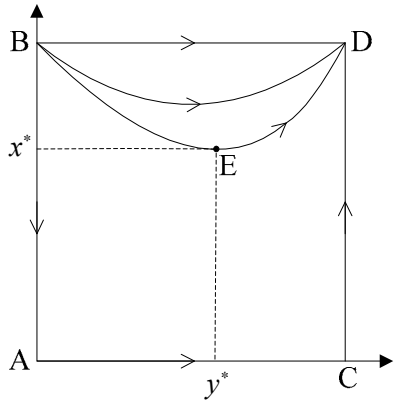

(a) Phase portrait I

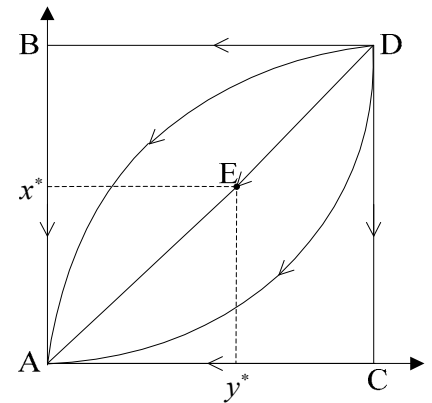

(d) Phase portrait IV

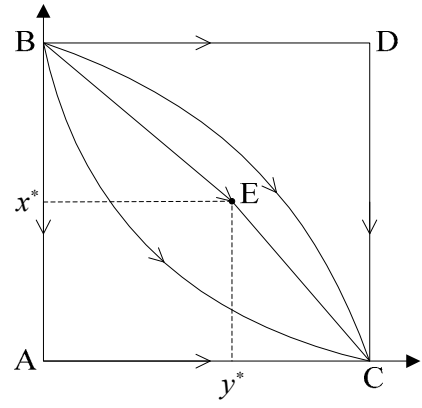

(b) Phase portrait II

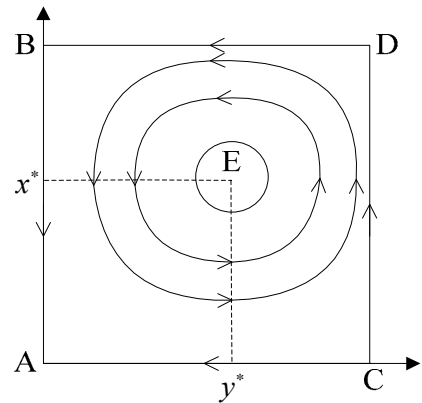

(e) Phase portrait $\mathrm{V}$

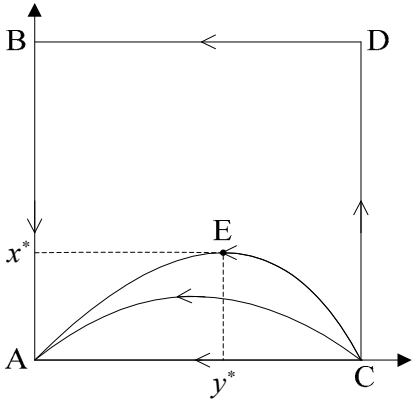

(c) Phase portrait III

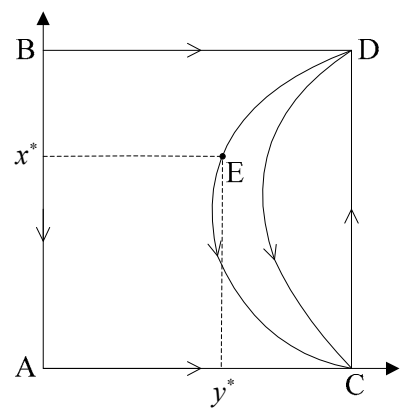

(f) Phase portrait VI

Figure 5. Phase portrait I IV.

\section{Numerical Analysis}

In this section, we outline the results of sensitivity analyses to complement the contents of Section 4. The classic Runge-Kutta method is applied to solve the differential equation group of the dynamic replicator system [42]. This numerical experiment is conducted on the simulation platform of MATLAB R2016a.

A MATLAB built-in function ode45 is utilized to obtain the numerical solutions. In this paper, the starting time of the evolution is set to 0 , and the terminal time is set to 10 . The initial point is $\mathrm{V}\left(X_{0}, Y_{0}\right)$, of which $0 \leq X_{0}, Y_{0} \leq 1$. In terms of the contents in Section 3, we assume the baseline: $P_{1}=10, P_{2}=10, L_{1}=15, F=5, W=10 R=15$.

\subsection{Verification to Phase Portrait I IV}

With the other parameters remaining the same, by setting $C_{1}=12$ and $C_{2}=8$, in this scenario, $L_{1}>C_{1}$ and $q\left(F+P_{1}+P_{2}\right)>C_{2}$. We randomly choose 50 points as the initial points; the evolution results can be depicted in panel (a) of Figure 6. We can see that the general tendency of the evolution paths is consistent with panel (a) in Figure 5.

With the other parameters remaining the same, by setting $C_{1}=12$ and $C_{2}=20$, in this scenario, $L_{1}>C_{1}$ and $q\left(F+P_{1}+P_{2}\right)<C_{2}$. Similarly, we randomly choose 50 points as the initial points. The general evolution tendency can be depicted in panel (b) of Figure 6, which is consistent with panel (b) in Figure 5.

With the other parameters remaining the same, by setting $C_{1}=35$ and $C_{2}=8$, in this scenario, $0<L_{1}<C_{1}-q(F+W)$ and $q\left(F+P_{1}+P_{2}\right)>C_{2}$. Similarly, we randomly choose 50 points as the initial points. The general evolution tendency can be depicted in panel (c) of Figure 6, which is consistent with panel (c) in Figure 5.

With the other parameters remaining the same, by setting $C_{1}=35$ and $C_{2}=20$, in this scenario, $0<L_{1}<C_{1}-q(F+W)$ and $q\left(F+P_{1}+P_{2}\right)<C_{2}$. We randomly choose 50 points as the initial points. 
The general evolution tendency can be depicted in panel (d) of Figure 6. We can see that the general tendency of the evolution paths is consistent with panel (d) in Figure 5.

With the other parameters remaining the same, by setting $C_{1}=20$ and $C_{2}=8$, in this scenario, $C_{1}-q(F+W)<L_{1}<C_{1}$ and $q\left(F+P_{1}+P_{2}\right)>C_{2}$. We randomly choose 50 points as the initial points. The general evolution tendency can be depicted in panel (e) of Figure 6. We can see that the general tendency of the evolution paths is consistent with panel (e) in Figure 5.

With the other parameters remaining the same, by setting $C_{1}=20$ and $C_{2}=20$, in this scenario, $C_{1}-q(F+W)<L_{1}<C_{1}$ and $q\left(F+P_{1}+P_{2}\right)<C_{2}$. We randomly choose 50 points as the initial points. The general evolution tendency can be depicted in panel (f) of Figure 6. We can see that the general tendency of the evolution paths is consistent with panel (f) in Figure 5.

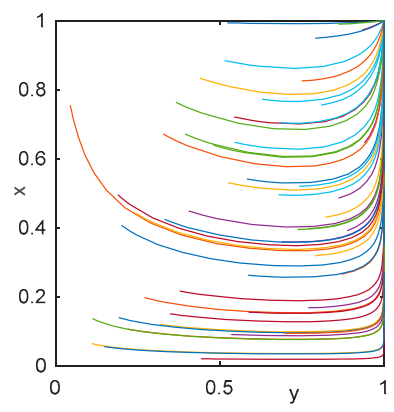

(a) Scenario I

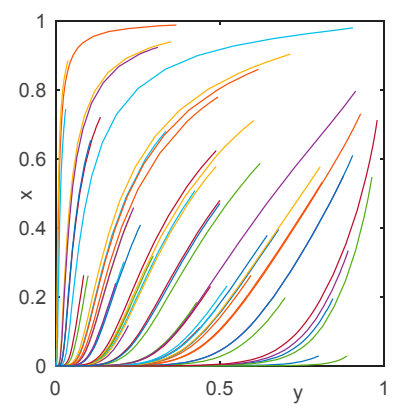

(d) Scenario IV

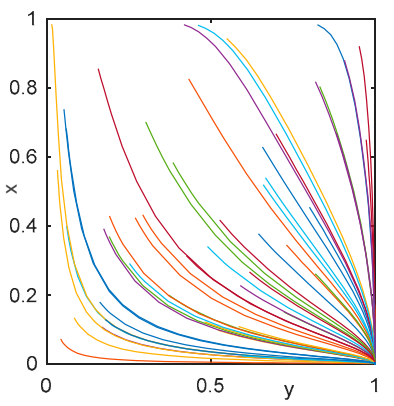

(b) Scenario II

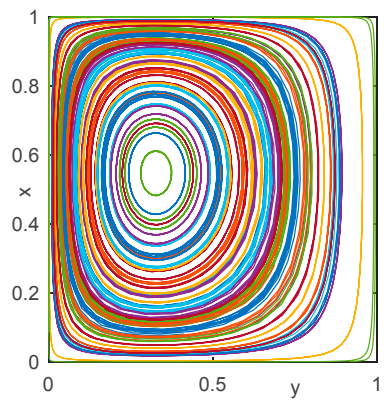

(e) Scenario V

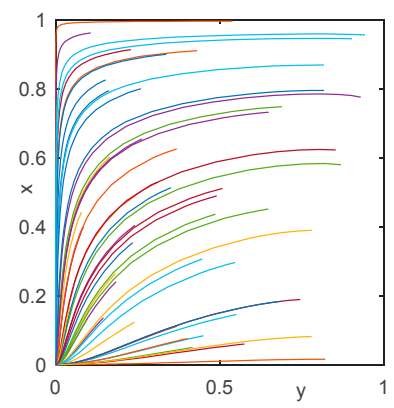

(c) Scenario III

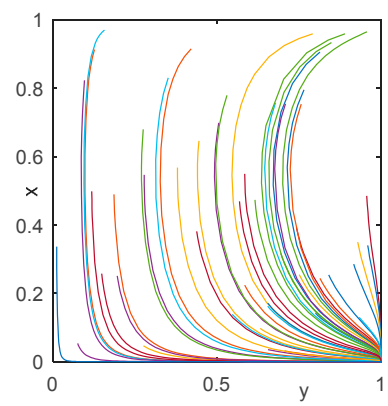

(f) Scenario VI

Figure 6. Evolution paths of scenarios I VI: (a) Scenario I; (b) Scenario II; (c) Scenario III; (d) Scenario IV; (e) Scenario V and (f) Scenario VI.

\subsection{Influences of Special Parameters}

By setting $C_{2}=8$, and keeping the other parameters consistent with the baseline, the initial point is $(0.5,0.5)$. Panels (a) and (b) in Figure 7 shows the results of the sensitivity analysis, in which $C_{1}$ increases from 10 to 50 with an addition of 10 . In panel (a), we can see that when $C_{1}$ increases, the dominant strategy of the government agency would change from supervision to no supervision. Reducing the implementation costs is helpful for more involvement from the government agency. In panel (b), we can see that when $C_{1}$ increases, the implementation probability of the enterprise decreases. Without supervision from the government agency, the enterprise would likely choose non-execution.

By setting $C_{1}=12$, and keeping the other parameters consistent with the baseline, the initial point is $(0.5,0.5)$. Panels (c) and (d) in Figure 7 show the results of the sensitivity analysis, in which $C_{2}$ increases from 5 to 25 with an addition of 5 . In panel (b), we can see that when $C_{2}$ increases, the implementation probability of the enterprise decreases. 


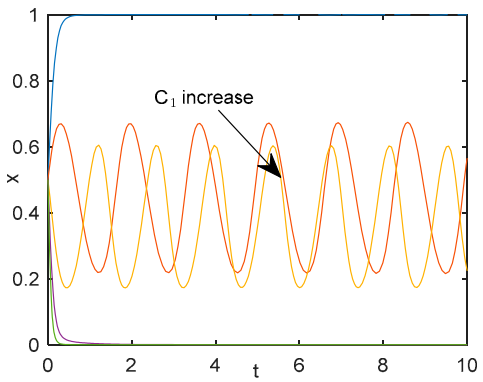

(a) Influences to the government agency

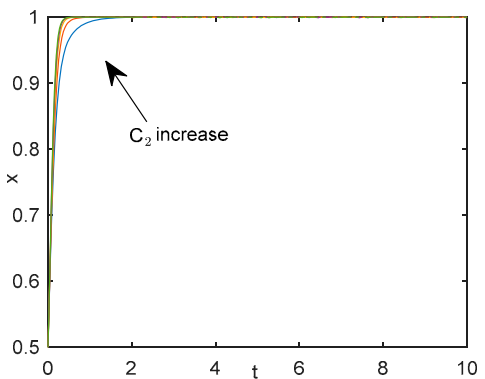

(c) Influences to the government agency

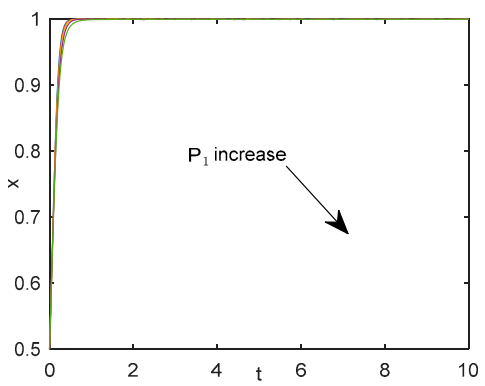

(e) Influences to the government agency

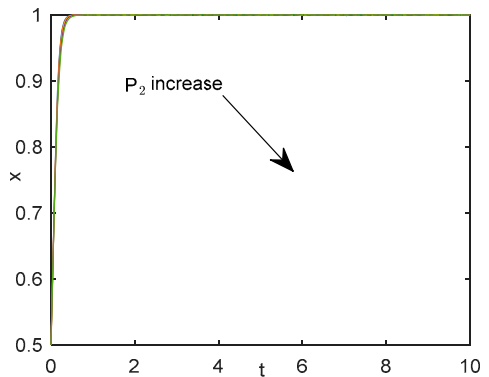

(g) Influences to the government agency

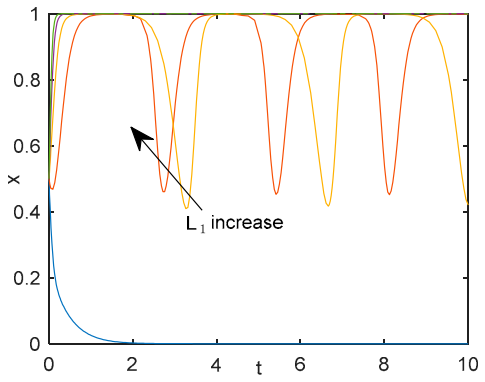

(i) Influences to the government agency

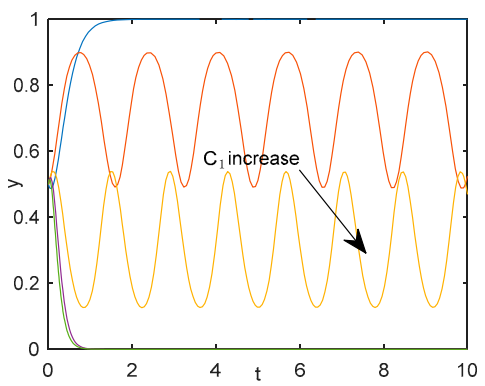

(b) Influences to the enterprise

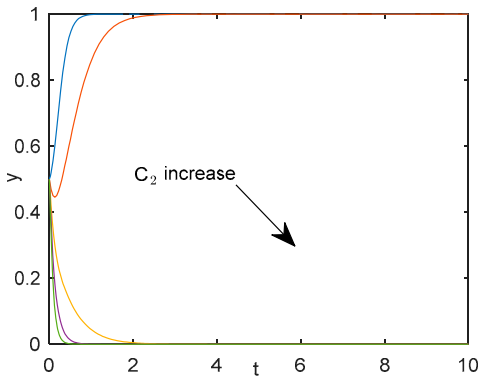

(d) Influences to the enterprise

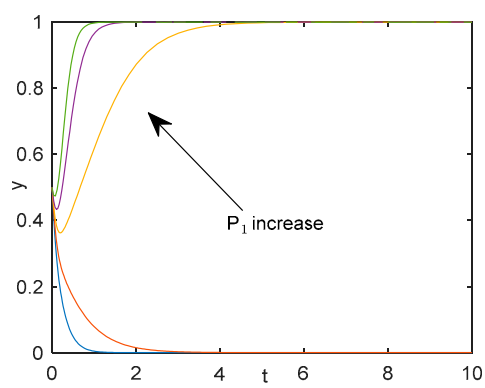

(f) Influences to the enterprise

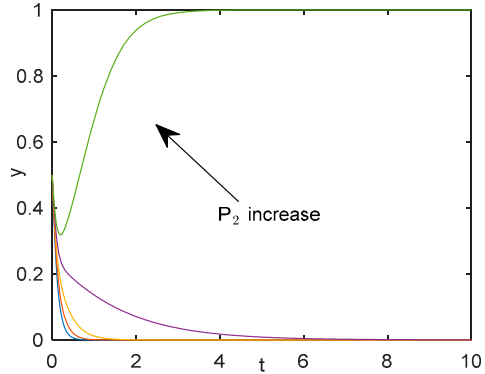

(h) Influences to the enterprise

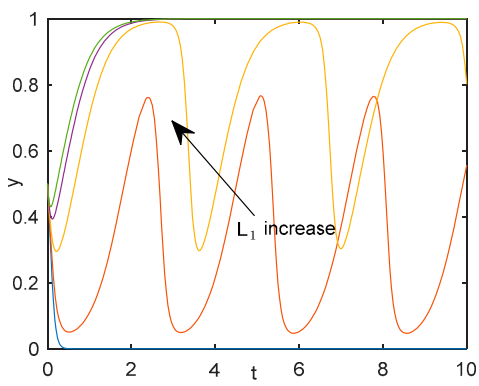

(j) Influences to the enterprise

Figure 7. Cont. 


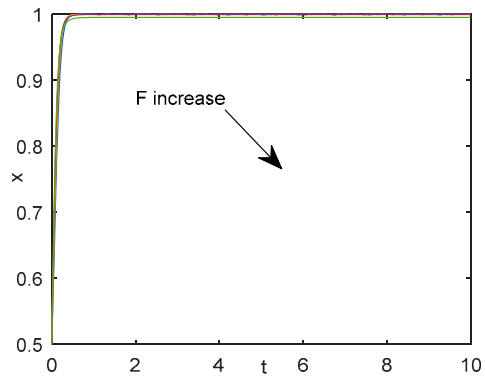

(k) Influences to the government agency

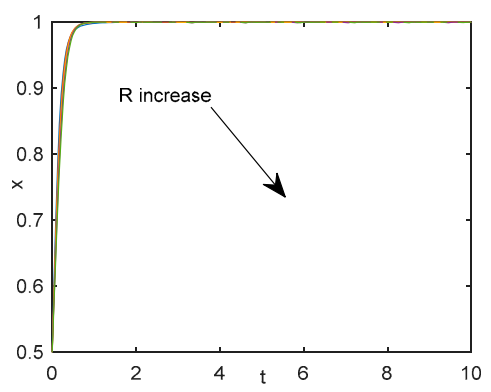

(m) Influences to the government agency

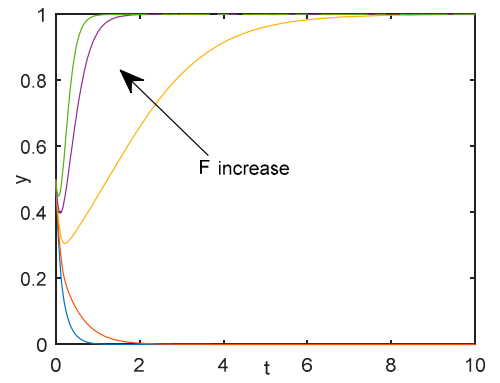

(1) Influences to the enterprise

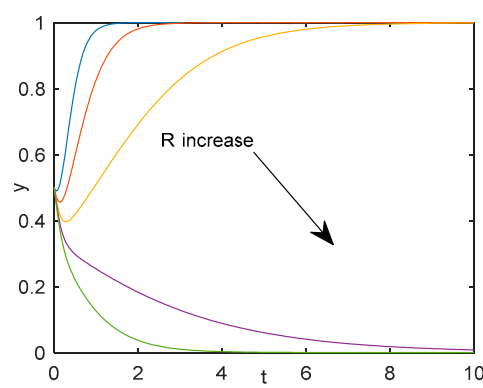

(n) Influences to the enterprise

Figure 7. Influences of game parameters.

By setting $C_{1}=12$ and $C_{2}=20$, and keeping the other parameters consistent with the baseline, the initial point is $(0.5,0.5)$. According to panel $(b)$ in Figure 5 , in this case, point $C(1,0)$ would be the ESS point. Panels (e) and (f) in Figure 7 show the results of the sensitivity analysis, in which $P_{1}$ increases from 10 to 50 with an addition of 10. In panel (f), we can see that when the influences from the customer side $\left(P_{1}\right)$ increase, the enterprise would likely choose to implement the standards.

By setting $C_{1}=12$ and $C_{2}=20$, and keeping the other parameters consistent with the baseline, the initial point is $(0.5,0.5)$. According to panel $(b)$ in Figure 5 , in this case, point $C(1,0)$ would be the ESS point. Panels $(\mathrm{g})$ and $(\mathrm{h})$ in Figure 7 show the results of the sensitivity analysis, in which $P_{2}$ increases from 5 to 25 with an addition of 5 . In panel (h), we can see that when the benefits from the government side $\left(P_{2}\right)$ increase, the enterprise would likely choose to implement the standards.

By setting $C_{1}=35$ and $C_{2}=20$, and keeping the other parameters consistent with the baseline, the initial point is $(0.5,0.5)$. According to panel $(\mathrm{d})$ in Figure 5 , in this case, point $\mathrm{A}(0,0)$ would be the ESS point. Panels (i) and (j) in Figure 7 show the results of the sensitivity analysis, in which $L_{1}$ increases from 10 to 50 with an addition of 10 . We can see that when the benefits from the public side $\left(L_{1}\right)$ increase, the government agency would like to choose the strategy $A_{1}$. With the implementation possibility of the government agency increasing, the enterprise would like to choose implementing the standards.

By setting $C_{1}=12$ and $C_{2}=20$, and keeping the other parameters consistent with the baseline, the initial point is $(0.5,0.5)$. According to panel $(b)$ in Figure 5 , in this case, point $C(1,0)$ would be the ESS point. Panels (k) and (l) in Figure 7 show the results of the sensitivity analysis, in which $F$ increases from 5 to 25 with an addition of 5 . From panel (l), we can see that to the enterprise, when the fines for non-execution acts $(F)$ increase, the enterprise would choose to implement the standards. The ESS point would switch from $\mathrm{C}(1,0)$ to $\mathrm{D}(1,1)$.

By setting $C_{1}=12$ and $C_{2}=8$, and keeping the other parameters consistent with the baseline, the initial point is $(0.5,0.5)$. According to panel (a) in Figure 5 , in this case, D $(1,1)$ would be the ESS point. Panels (m) and (n) in Figure 7 show the results of the sensitivity analysis, in which $R$ increases from 15 to 35 with an addition of 5 . In panel (n), we can see that to the enterprise, when the supervision 
effectiveness of the government agency decreases ( $R$ increases), the enterprise would tend to choose the strategy of non-execution, in which case the ESS point would switch from $D(1,1)$ to $C(1,0)$.

\section{Conclusions and Policy Implications}

This paper has focused on the problem in the eco-labeling scheme of how to regulate and supervise the enterprises after they are certified, while also taking into consideration that the existing eco-labeling schemes in different countries are very different, and different certification systems and standards would result in different interaction relationships among stakeholders. We especially focus on the CEL scheme and study the strategic interactions between the government agency and enterprise by utilizing the approach of evolutionary game theory. With the supplement of numerical analyses, five propositions are proposed. Our results indicate that:

1. Combined with the analyses in Proposition 1 , we can see that in any case, the strategy combination $\left(A_{2}, B_{1}\right)$ could not be a stable equilibrium solution. Namely, without effective supervision, a for-profit enterprise would not fulfill its duty spontaneously.

2. According to panel (a) in Figure 7, when the supervision costs of the government agency increase, the government agency would choose not to supervise. In terms of panel $(\mathrm{m})$, if the supervision efficiency of the government agency was low, the enterprise would tend to not implement the standards.

3. In terms of panel (d) in Figure 7, when the implementation costs of the enterprise increase, the enterprise would not like to implement the standards.

4. Combined with the panel (l) in Figure 7, we can see that when the fines for the non-execution acts of an enterprise increase, it would like to choose to implement the standards.

5. As presented by panels (f) and (h) in Figure 7, when the influences from the government and customer side increase, the enterprises tend to choose to implement the standards.

Under the assumptions and parameter settings in this paper, the strategy combination (not supervise, implement) could not be a stable equilibrium. In line with the current situation, supervision from the government side is necessary in order for the enterprise to implement the standards.

For the government agency, high supervision costs and low efficiency are the two main obstructive factors. In this case, on the one hand, regarding Figure 3, in the following stage, the government could consider bringing public scrutiny into the supervision system, which would be helpful for reducing informational asymmetries between the government agency and the enterprise. On the other hand, the participation of a third-party agency and company would not only benefit through reducing supervision costs, it would also be helpful through contributing to improving the effects of supervision $[5,19]$.

For the enterprise, high implementation cost is an important factor that impedes it from getting more involved. Reducing the execution costs of enterprises is helpful in making them participate more. In this case, government agencies can offer some subsidies or tax reductions to the enterprises [21]. Except for imposing a fine, a government agency such as the CEC needs to integrate the supervision information. A public information platform is necessary to disclose these dishonest enterprises and pipe them off from government procurement.

In addition, to encourage the enterprises to implement the standards spontaneously, on the one hand, the government should provide more priorities to labeled products. On the other hand, more publicity about the eco-label should be visible to the public, which would help to raise the green consumption awareness of consumers. All of those measures are helpful for moving the equilibrium point toward the strategy combination (not supervise, implement) [43].

Although our research is mainly motivated by the issues that exist in China, the analyses and proposed policy suggestions are also suitable for many countries, especially some large developing countries. Given the limited space available, an evaluation of the effectiveness of these proposals 
above cannot be discussed in detail in this paper, which can be modeled by incorporating additional factors such as tax, publicity costs, and so on.

In this paper, we specially focus on the eco-labeling scheme launched by the government. We treat government agencies such as the CEC and AIC as a whole, and do not consider their personal incentives. That is one drawback of this paper. In the following study, we would take these factors into account, as well as the influences from other certification organizations such as businesses and non-governmental organizations (NGOs). Studying the conflicting interests among them would make the study more comprehensive and practical. On the other hand, we also do not consider how many rounds are required to achieve equilibrium. In fact, if the interaction between the enterprise and the government agency was finite, evolutionary game theory would not be suitable for this issue. In that case, a supergame between the enterprise and the government agency should be modeled, and then the folk theorem would kick in.

The value of this paper is limited in that the data used in the numerical analysis is not real. In the following research, we would conduct an empirical analysis to verify the results and supplement the contents of this paper. Also, our paper analyzes the interaction relationships between the government agencies and enterprises. In future research, the consumer would be added to the game as a third player, which would make the study more valuable. Recently, a series of new information technologies have been adopted by the Chinese government to regulate the labeled enterprises, such as the Internet of Things and data mining. The influences of these factors should also be modeled in future research.

Author Contributions: Conceptualization, J.J. and Q.Z.; Methodology, J.J. and Q.Z.; Formal Analysis, J.J. and J.Z.; Writing-Original Draft Preparation, J.J. and J.Z.; Writing-Review \& Editing, J.J. and J.Z.

Funding: This work is funded by the National Natural Science Foundation of China (NSFC) under Grants Nos. 71471006 and 91224007 . The supports are gratefully acknowledged.

Conflicts of Interest: The authors declare no conflicts of interest.

\section{Appendix A}

For any point, $\operatorname{det} J=\frac{\partial f_{A}}{\partial x} * \frac{\partial f_{B}}{\partial y}-\frac{\partial f_{A}}{\partial y} * \frac{\partial f_{B}}{\partial x}$, and $\operatorname{tr} J=\frac{\partial f_{A}}{\partial x}+\frac{\partial f_{B}}{\partial y}$. In terms of Formula (11), the specific values of $\operatorname{det} J$ and $\operatorname{tr} J$ in LEP points $\mathrm{A} \sim \mathrm{E}$ can be obtained as follows:

Table A1. Definitions of the notations used in the paper.

\begin{tabular}{ll}
\hline LEP & The Determinant and Trace of $J$ \\
\hline $\mathrm{A}(0,0)$ & $\begin{array}{l}\operatorname{det} J=\left[-C_{1}+L_{1}+q(F+W)\right]\left(-C_{2}\right) \\
\operatorname{tr} J=-C_{1}+L_{1}+q(F+W)-C_{2}\end{array}$ \\
\hline $\mathrm{B}(0,1)$ & $\begin{array}{l}\operatorname{det} J=C_{2}\left(-C_{1}+L_{1}\right) \\
\operatorname{tr} J=-C_{1}+L_{1}+C_{2}\end{array}$ \\
\hline $\mathrm{C}(1,0)$ & $\begin{array}{l}\operatorname{det} J=-\left[-C_{1}+L_{1}+q(F+W)\right]\left[q\left(F+P_{1}+P_{2}\right)-C_{2}\right] \\
\operatorname{tr} J=C_{1}-L_{1}-q(F+W)+q\left(F+P_{1}+P_{2}\right)-C_{2}\end{array}$ \\
\hline $\mathrm{D}(1,1)$ & $\begin{array}{l}\operatorname{det} J=\left(-C_{1}+L_{1}\right)\left[q\left(F+P_{1}+P_{2}\right)-C_{2}\right] \\
\operatorname{trJ}=C_{1}-L_{1}-q\left(F+P_{1}+P_{2}\right)+C_{2}\end{array}$ \\
\hline $\mathrm{E}\left(x^{*}, y^{*}\right)$ & $\begin{array}{l}\operatorname{det} J=y^{*}\left(1-y^{*}\right) q\left(F+P_{1}+P_{2}\right)+x^{*}\left(1-x^{*}\right) q(F+W) \\
\operatorname{trJ}=0\end{array}$ \\
\hline
\end{tabular}

\section{Appendix B}

Proof to Proposition 1. To B $(0,1)$, det $J=C_{2}\left(-C_{1}+L_{1}\right)$ and $\operatorname{tr} J=-C_{1}+L_{1}+C_{2}$. If the value of $C_{1}$ was larger than $L_{1}$, this would result in $-C_{1}+L_{1}<0 \Rightarrow \operatorname{det} J=C_{2}\left(-C_{1}+L_{1}\right)<0$. In this scenario, point $B$ was a saddle point; if the value of $C_{1}$ was less than $L_{1}$, this would result in det $J=C_{2}\left(-C_{1}+L_{1}\right)>0$ and $\operatorname{tr} J=-C_{1}+L_{1}+C_{2}>0$. In this scenario, point $\mathrm{B}$ was 
an unstable point. If the value of $C_{1}$ was equal to $L_{1}$, this would result in $\operatorname{det} J=C_{2}\left(-C_{1}+L_{1}\right)=0$ and $\operatorname{tr} J=C_{2}>0$. In this scenario, point $\mathrm{B}$ was an unstable point. Hence, in any case, point $\mathrm{B}$ could not be a stable point, and the corresponding strategy combination $\left(A_{2}, B_{1}\right)$ would not be a stable equilibrium solution.

\section{Appendix C}

When $L_{1}=C_{1}, L_{1}=C_{1}-q(F+W)$ or $q\left(F+P_{1}+P_{2}\right)=C_{2}$, all of the possible scenarios of five local equilibrium points are shown in Tables A2-A10.

When $L_{1}=C_{1}$ and $q\left(F+P_{1}+P_{2}\right)>C_{2}$, the state of five local equilibrium points can be shown in Table A2.

Table A2. State analysis of LEP.

\begin{tabular}{cccc}
\hline LEP & det $J$ & trJ & State \\
\hline $\mathrm{A}(0,0)$ & - & uncertain & saddle \\
$\mathrm{B}(0,1)$ & 0 & + & unstable \\
$\mathrm{C}(1,0)$ & - & uncertain & saddle \\
$\mathrm{D}(1,1)$ & 0 & - & general \\
$\mathrm{E}\left(x^{*}, y^{*}\right)$ & + & 0 & neutral \\
\hline
\end{tabular}

When $L_{1}=C_{1}$ and $q\left(F+P_{1}+P_{2}\right)<C_{2}$, the state of five local equilibrium points can be shown in Table A3.

Table A3. State analysis of LEP.

\begin{tabular}{cccc}
\hline LEP & det $J$ & trJ & State \\
\hline $\mathrm{A}(0,0)$ & - & uncertain & saddle \\
$\mathrm{B}(0,1)$ & 0 & + & unstable \\
$\mathrm{C}(1,0)$ & + & - & ESS \\
$\mathrm{D}(1,1)$ & 0 & + & unstable \\
$\mathrm{E}\left(x^{*}, y^{*}\right)$ & + & 0 & neutral \\
\hline
\end{tabular}

When $L_{1}=C_{1}-q(F+W)$ and $q\left(F+P_{1}+P_{2}\right)>C_{2}$, the state of five local equilibrium points can be shown in Table A4.

Table A4. State analysis of LEP.

\begin{tabular}{cccc}
\hline LEP & $\operatorname{det} J$ & $\operatorname{tr} J$ & State \\
\hline $\mathrm{A}(0,0)$ & 0 & - & general \\
$\mathrm{B}(0,1)$ & - & uncertain & saddle \\
$\mathrm{C}(1,0)$ & 0 & + & unstable \\
$\mathrm{D}(1,1)$ & - & uncertain & saddle \\
$\mathrm{E}\left(x^{*}, y^{*}\right)$ & + & 0 & neutral \\
\hline
\end{tabular}

When $L_{1}=C_{1}-q(F+W)$ and $q\left(F+P_{1}+P_{2}\right)<C_{2}$, the state of five local equilibrium points can be shown in Table A5. 
Table A5. State analysis of LEP.

\begin{tabular}{cccc}
\hline LEP & $\operatorname{det} \boldsymbol{J}$ & trJ & State \\
\hline $\mathrm{A}(0,0)$ & 0 & - & general \\
$\mathrm{B}(0,1)$ & - & uncertain & saddle \\
$\mathrm{C}(1,0)$ & 0 & - & general \\
$\mathrm{D}(1,1)$ & + & + & unstable \\
$\mathrm{E}\left(x^{*}, y^{*}\right)$ & + & 0 & neutral \\
\hline
\end{tabular}

When $0<L_{1}<C_{1}-q(F+W)$ and $q\left(F+P_{1}+P_{2}\right)=C_{2}$, the state of five local equilibrium points can be shown in Table A6.

Table A6. State analysis of LEP.

\begin{tabular}{cccc}
\hline LEP & det $J$ & trJ & State \\
\hline $\mathrm{A}(0,0)$ & + & - & ESS \\
$\mathrm{B}(0,1)$ & - & uncertain & saddle \\
$\mathrm{C}(1,0)$ & 0 & + & unstable \\
$\mathrm{D}(1,1)$ & 0 & + & unstable \\
$\mathrm{E}\left(x^{*}, y^{*}\right)$ & + & 0 & neutral \\
\hline
\end{tabular}

When $C_{1}-q(F+W)<L_{1}<C_{1}$ and $q\left(F+P_{1}+P_{2}\right)=C_{2}$, the state of five local equilibrium points can be shown in Table A7.

Table A7. State analysis of LEP.

\begin{tabular}{cccc}
\hline LEP & $\operatorname{det} J$ & trJ & State \\
\hline $\mathrm{A}(0,0)$ & - & uncertain & saddle \\
$\mathrm{B}(0,1)$ & - & uncertain & saddle \\
$\mathrm{C}(1,0)$ & 0 & - & general \\
$\mathrm{D}(1,1)$ & 0 & + & unstable \\
$\mathrm{E}\left(x^{*}, y^{*}\right)$ & + & 0 & neutral \\
\hline
\end{tabular}

When $L_{1}>C_{1}$ and $q\left(F+P_{1}+P_{2}\right)=C_{2}$, the state of five local equilibrium points can be shown in Table A8.

Table A8. State analysis of LEP.

\begin{tabular}{cccc}
\hline LEP & $\operatorname{det} \boldsymbol{J}$ & tr $\boldsymbol{~}$ & State \\
\hline $\mathrm{A}(0,0)$ & - & uncertain & saddle \\
$\mathrm{B}(0,1)$ & + & + & unstable \\
$\mathrm{C}(1,0)$ & 0 & - & general \\
$\mathrm{D}(1,1)$ & 0 & - & general \\
$\mathrm{E}\left(x^{*}, y^{*}\right)$ & + & 0 & neutral \\
\hline
\end{tabular}

When $L_{1}=C_{1}-q(F+W)$ and $q\left(F+P_{1}+P_{2}\right)=C_{2}$, the state of five local equilibrium points can be shown in Table A9. 
Table A9. State analysis of LEP.

\begin{tabular}{cccc}
\hline LEP & $\operatorname{det} \boldsymbol{J}$ & trJ & State \\
\hline $\mathrm{A}(0,0)$ & 0 & - & general \\
$\mathrm{B}(0,1)$ & - & uncertain & saddle \\
$\mathrm{C}(1,0)$ & 0 & 0 & general \\
$\mathrm{D}(1,1)$ & 0 & + & general \\
$\mathrm{E}\left(x^{*}, y^{*}\right)$ & + & 0 & neutral \\
\hline
\end{tabular}

When $L_{1}=C_{1}$ and $q\left(F+P_{1}+P_{2}\right)=C_{2}$, the state of five local equilibrium points can be shown in Table A10.

Table A10. State analysis of LEP.

\begin{tabular}{cccc}
\hline LEP & $\operatorname{det} \boldsymbol{J}$ & tr $\boldsymbol{~}$ & State \\
\hline $\mathrm{A}(0,0)$ & - & uncertain & saddle \\
$\mathrm{B}(0,1)$ & 0 & + & unstable \\
$\mathrm{C}(1,0)$ & 0 & - & general \\
$\mathrm{D}(1,1)$ & 0 & 0 & general \\
$\mathrm{E}\left(x^{*}, y^{*}\right)$ & + & 0 & neutral \\
\hline
\end{tabular}

\section{References}

1. Amacher, G.S.; Koskela, E.; Ollikainen, M. Environmental quality competition and eco-labeling. J. Environ. Econ. Mang. 2004, 47, 284-306. [CrossRef]

2. Cai, Z.; Xie, Y.; Aguilar, F.X. Eco-label credibility and retailer effects on green product purchasing intentions. Forest. Policy Econ. 2017, 80, 200-208. [CrossRef]

3. Bleda, M.; Valente, M. Graded eco-labels: A demand-oriented approach to reduce pollution. Technol. Forecast. Soc. Chang. 2009, 76, 512-524. [CrossRef]

4. Daugbjerg, C.; Smed, S.; Andersen, L.M.; Schvartzman, Y. Improving eco-labelling as an environmental policy instrument: Knowledge, trust and organic consumption. J. Environ. Policy Plan. 2014, 16, 559-575. [CrossRef]

5. Schumacher, I. Ecolabeling, consumers' preferences and taxation. Ecol. Econ. 2010, 69, 2202-2212. [CrossRef]

6. Lyon, T.P.; Montgomery, A.W. The means and end of greenwash. Organ. Environ. 2015, 28, 21-36. [CrossRef]

7. Lyon, T.P.; Maxwell, J.W. Greenwash: Corporate Environmental Disclosure under Threat of Audit. J. Econ. Manag. Startegy 2011, 20, 3-41. [CrossRef]

8. Rahbar, E.; Wahid, N.A. Investigation of green marketing tools' effect on consumers' purchase behavior. Bus. Strategy Ser. 2011, 12, 73-83. [CrossRef]

9. D'Souza, C.; Taghian, M.; Lamb, P.; Peretiatkos, R. Green products and corporate strategy: An empirical investigation. Soc. Bus. Rev. 2006, 1, 144-157. [CrossRef]

10. Laufer, W.S. Social accountability and corporate greenwashing. J. Bus. Ethics 2003, 43, 253-261. [CrossRef]

11. Sustainable Efforts and Environmental Concerns around the World: A Nielsen Report. Available online: http: / /hk.nielsen.com/documents/NielsenSustainabilityReportAug2011FINAL (accessed on 25 February 2018).

12. Castka, P.; Prajogo, D. The effect of pressure from secondary stakeholders on the internalization of ISO 14001. J. Clean. Prod. 2013, 47, 245-252. [CrossRef]

13. Delmas, M.A.; Burbano, V.C. The drivers of greenwashing. Calif. Manag. Rev. 2011, 54, 64-87. [CrossRef]

14. Du, X. How the Market Values Greenwashing? Evidence from China. J. Bus. Ethics 2015, 128, 547-574. [CrossRef]

15. Testa, F.; Boiral, O.; Iraldo, F. Internalization of environmental practices and institutional complexity: Can stakeholders pressures encourage greenwashing? J. Bus. Ethics 2015, 147, 287-307. [CrossRef] 
16. Brécard, D. Consumer confusion over the profusion of eco-labels: Lessons from a double differentiation model. Resour. Energy Econ. 2014, 37, 64-84. [CrossRef]

17. Harbaugh, R.; Maxwell, J.W.; Roussillon, B. Label confusion: The groucho effect of uncertain standards. Manag. Sci. 2011, 57, 1512-1527. [CrossRef]

18. Houe, R.; Grabot, B. Assessing the compliance of a product with an eco-label: From standards to constraints. Int. J. Prod. Econ. 2009, 121, 21-38. [CrossRef]

19. Roe, B.; Sheldon, I. Credence good labeling: The efficiency and distributional implications of several policy approaches. Am. J. Agric. Econ. 2007, 89, 1020-1033. [CrossRef]

20. Crespi, J.M.; Marette, S. How should food safety certification be financed? Am. J. Agric. Econ. 2001, 83, 852-861. [CrossRef]

21. Hamilton, S.F.; Zilberman, D. Green markets, eco-certification, and equilibrium fraud. J. Environ. Econ. Manag. 2006, 52, 627-644. [CrossRef]

22. Zhou, Y. The role of green customers under competition: A mixed blessing? J. Clean. Prod. 2018, 170, 857-866. [CrossRef]

23. Dahl, R. Green washing: Do you know what you're buying? Environ. Health Perspect. 2010, 118, A246. [CrossRef] [PubMed]

24. Chekima, B.; Wafa, S.A.W.S.K.; Igau, O.A.; Chekima, S.; Sondoh, S.L.S., Jr. Examining green consumerism motivational drivers: Does premium price and demographics matter to green purchasing? J. Clean. Prod. 2016, 112, 3436-3450. [CrossRef]

25. Jenkins, H.; Yakovleva, N. Corporate social responsibility in the mining industry: Exploring trends in social and environmental disclosure. J. Clean. Prod. 2006, 14, 271-284. [CrossRef]

26. Orlitzky, M.; Siegel, D.S.; Waldman, D. Strategic corporate social responsibility and environmental sustainability. Bus. Soc. 2011, 50, 6-27. [CrossRef]

27. Apaloo, J.; Brown, J.S.; Vincent, T.L. Evolutionary game theory: ESS, convergence stability, and NIS. Evol. Ecol. Res. 2009, 11, 489-515.

28. Cressman, R. Stability of the replicator equation with continuous strategy space. Math. Soc. Sci. 2005, 50, 127-147. [CrossRef]

29. Friedman, D. Evolutionary games in economics. Econometric 1991, 59, 637-666. [CrossRef]

30. Laan, G.V.D.; Tieman, X. Evolutionary game theory and the modelling of economic behavior. De Economist 1998, 146, 59-89.

31. Liu, Q.; Yan, Z.; Zhou, J. Consumer choices and motives for Eco-Labeled products in china: An empirical analysis based on the choice experiment. Sustainability 2017, 9, 331. [CrossRef]

32. Min, S.H.; Lim, S.Y.; Yoo, S.H. Consumers' willingness to pay a premium for eco-labeled LED TVs in Korea: A contingent valuation study. Sustainability 2017, 9, 814.

33. Wuepper, D.; Heissenhuber, A.; Sauer, J. Investigating rice farmers' preferences for an agri-environmental scheme: Is an eco-label a substitute for payments? Land Use Policy 2017, 64, 374-382.

34. Steiner, B.E.; Peschel, A.O.; Grebitus, C. Multi-Product Category Choices Labeled for Ecological Footprints: Exploring Psychographics and Evolved Psychological Biases for Characterizing Latent Consumer Classes. Ecol. Econ. 2017, 140, 251-264. [CrossRef]

35. The Certification of CEL. Available online: http://kjs.mep.gov.cn/zghjbz/ (accessed on 25 February 2018).

36. Lozano, J.; Blanco, E.; Rey-Maquieira, J. Can ecolabels survive in the long run? The role of initial conditions. Ecol. Econ. 2010, 69, 2525-2534. [CrossRef]

37. Prieto-Sandoval, V.; Alfaro, J.A.; Mejía-Villa, A.; Ormazabal, M. ECO-labels as a multidimensional research topic: Trends and opportunities. J. Clean. Prod. 2016, 135, 806-818. [CrossRef]

38. Milovantseva, N. Are American households willing to pay a premium for greening consumption of Information and Communication Technologies? J. Clean. Prod. 2016, 127, 282-288. [CrossRef]

39. Sandholm, W.H.; Dokumac1, E.; Lahkar, R. The projection dynamic and the replicator dynamic. Games Econ. Behav. 2008, 64, 666-683. [CrossRef]

40. Friedman, D. On economic applications of evolutionary game theory. J. Evol. Econ. 1998, 8, 15-43. [CrossRef] 
41. Roca, C.P.; Cuesta, J.A.; Sánchez, A. Evolutionary game theory: Temporal and spatial effects beyond replicator dynamics. Phys. Life Rev. 2009, 6, 208-249. [CrossRef] [PubMed]

42. Cameron, I.T.; Gani, R. Adaptive Runge-Kutta algorithms for dynamic simulation. Comput. Chem. Eng. 1988, 12, 705-717. [CrossRef]

43. Bladh, M. Eco-Standards, product labelling and green consumerism. Int. J. Consum. Stud. 2009, 33, 356-357.

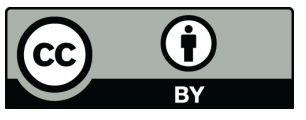

(c) 2018 by the authors. Licensee MDPI, Basel, Switzerland. This article is an open access article distributed under the terms and conditions of the Creative Commons Attribution (CC BY) license (http:/ / creativecommons.org/licenses/by/4.0/). 